\title{
Do desenho ao mito, passando pelo simbólico, na escola de educação infantil
}

\author{
Maria das Vitórias Negreiros do Amaral \\ Universidade Federal de Pernambuco
}

\section{RESUMO}

Este texto é baseado na pesquisa tem como fio condutor a Teoria do Imaginário, de Gilbert Durand. Para compreender como os sujeitos sociais apreendem a arte, fui a quatro escolas que têm como proposta a inserção da arte em seus currículos. Com o objetivo de observar as crianças que estão iniciando o processo de ensino-aprendizagem escolar, foi feita pesquisa de campo em quatro turmas de crianças com faixa etária entre 4 e 6 anos. Analisando o material recolhido no campo: etnografia, testes AT-10 (Teste Arquetipal de 10 elementos), entrevistas e os históricos escolares, constatei que essas escolas têm um discurso explícito de criar um "espaço feliz", que tem como base do aprendizado o lúdico e a arte. Pode-se ver esse discurso como sendo regido pelo mito de Orfeu, que doma as feras e diante de quem as árvores se dobram, ao som de sua lira. Entretanto, as crianças vivem no mundo de Dionísio, vivem num mundo de jogo e de brincadeira. A noção de arte é repassada para a criança, pela escola, através da: arte como prazer, transformada em arte como crescimento; e o aprendizado da arte.

Palavras-chave: Ensino de Arte, Educação Infantil, Antropologia do Imaginário.

\section{RÉSUMEN}

Este texto se basa en la investigación en la linea teórica del imaginario, de Gilbert Durand. Para entender cómo los sujetos sociales perciben el arte, fui a cuatro escuelas cuya propuesta el arte de la inclusión en sus planes de estudio. Con el fin de observar a los niños que están empezando el proceso de enseñanza-aprendizaje de la escuela, la investigación de campo se llevó a cabo en cuatro clases, los niños de edades comprendidas entre los 4 y 6 años. Analizando el material recolectado en el campo: la etnografía, AT-10 pruebas (Test arquetípica 10 elementos), entrevistas y transcripciones, me encontré con que estas escuelas tienen una dirección explícita para crear un "espacio feliz", cuyo aprendizaje basado en lúdica y el arte. Uno puede ver este discurso como siendo gobernado por el mito de Orfeo, que amansa a las fieras y los que los árboles se doblan con el sonido de su lira. Sin embargo, los niños que viven en el mundo de Dioniso, viven en un mundo 
de juego y diversión. La noción de arte se transmite al niño de la escuela a través de: el arte como placer, transformado en el arte como el crecimiento; y el aprendizaje del arte.

Palabras-clave: Enseñanza del arte, Educación Infantil, Antropolgía del Imaginarío.

\section{Introdução}

Para captar como as crianças apreendem o conhecimento de arte, fiz, de quatro escolas privadas de Educação Infantil, da cidade do Recife, meu campo de pesquisa. Essas escolas têm como proposta a inserção da arte em seus currículos, com o objetivo de observar as crianças que estão iniciando o processo de ensino-aprendizagem escolar. Para aprofundar esse conhecimento, trabalhei especificamente com crianças de faixa etária entre quatro e seis anos de idade, em turmas de Educação Infantil II.

Os teóricos que fundamentaram esta pesquisa foram Gilbert Durand, Edgar Morin, sobre as questões do imaginário; Jean-Jacques Wunenburger, filósofo das imagens; Ana Mae Barbosa, acerca de arte/educação; Bruno Duborgel e Maria Cecília Teixeira Sanches, referente à educação e ao imaginário.

As imagens encontradas e selecionadas para esta pesquisa foram as produzidas pelas crianças, expressas através do corpo, do discurso, das narrativas e dos desenhos feitos no papel ou em outro material plástico (barro, massinha de modelar, etc.), pois:

Se a imagem é registrada através dos sentidos externos, convém não negligenciar essas atividades motoras, uma vez que o corpo é para o sujeito encarnado um instrumento de receptividade sensorial, e também de atividade motora. Ele desenvolve uma imagerie $^{41}$, interna e funcional, como no esquema corporal; externa, através de suas expressões mímicas e gestuais, involuntárias ou controladas. Deste ponto de vista, a imagem corporal é um intermediário psicofísico que assegura o bom cumprimento das posturas, gestos e condutas (WUNENBURGER, 1997, p.13).

E é por isso que tentei compreender o desenho sem separá-lo das outras atividades artísticas em que as crianças realizam, sem necessariamente optar por desenhar, dançar, cantar ou contar histórias... A criança não fragmenta as linguagens "enquanto desenha, canta, dança, conta histórias, teatraliza, imagina, ou até silencia... O ato de desenhar impulsiona outras manifestações, que acontecem juntas, numa unidade indissolúvel” (DERDYK, 1989, p.19).

Analisando o material recolhido na pesquisa de campo, na etnografia, nos testes AT-10 (teste arquetipal de 10 elementos, reelaboração feita pela Profa ${ }^{\text {a }}$ Danielle R. Pitta 
do AT-9 criado por Yves Durand), nas entrevistas e nos históricos escolares, constatei que as escolas pesquisadas têm um discurso explícito de criar um "espaço feliz", sendo esse fundado no lúdico e na arte. Esse discurso pode ser apreendido através do mito de Orfeu, que doma as feras e diante de quem as árvores se dobram, ao som da lira. Inserida nesse mesmo discurso, há outra dimensão, a do Tácito, que está nas entrelinhas do explícito, e é através dele que a escola (instituição escolar) passa as regras sociais para a formação de um "futuro homem" ou um "homem do futuro", num mundo competitivo, onde o que tem "valor" é um produto a ser consumido. Entretanto, as crianças vivem no mundo de Dionísio, num mundo de jogo e de brincadeira.

No pensamento racionalizado da escola, para que a criança internalize o sentido de competição e para que essa tenha efeito, o exercício da quantificação é fundamental no cotidiano escolar, pois na hora de fazer um teste para entrar numa escola, temos, muitas vezes, 3.000 crianças para 50 vagas, e é importante que se tenha essa consciência de que passarão no teste apenas as crianças que conseguirem alcançar mais pontos nas provas e isso desde o primeiro ano do Ensino Fundamental, período em que as crianças têm de seis a sete anos.

Mas a lógica [tradição do pensamento que forma o espírito das escolas elementares] a que obedece, estende sobre a sociedade e as relações humanas as restrições e os mecanismos inumanos da máquina artificial com sua visão determinista, mecanicista, quantitativa, formalista que ignora, oculta ou dissolve tudo o que é subjetivo, afetivo, livre e criador (MORIN 1999, p. 11).

Nas quatro escolas que compuseram nosso campo de pesquisa, as professoras avaliam as atividades do dia, no final do horário, perguntando: "O que vocês mais gostaram de fazer hoje?" 42 . Em um dos dias observados, as crianças responderam que "desenhar" foi a atividade mais apreciada. De dezesseis crianças, o desenho venceu, de quatorze votos a dois, para a modelagem de massinha, outra atividade artística realizada em sala. As demais atividades não tiveram nenhum voto - o que sugere que, dentre uma quantidade enorme de exercícios de fixação, em que o objetivo é a "quantidade"; as crianças preferem atividades artísticas e lúdicas.

Essa dimensão do discurso, a tácita, é regida pelo mito de Prometeu, o mito do progresso. Aumentando a constelação de imagens dessa dimensão da escola, podemos observar que "saber comportar-se como um adulto" é, também, preparar-se para a competição no mercado de trabalho, onde o "tempo vale ouro". Então, "a hora de trabalhar não é para brincar, dançar, descansar ou contar aventuras”, pois o tempo, como é utilizado na escola, fragmenta as atividades; enquanto o tempo para criança não precisa

||||||||||||||||||||||||||||||||||||||||||||||||||||||||||

42 Os textos numa diagramação diferente e com letra 11, são trechos retirados da pesquisa de campo, encontrados na Dissertação de Mestrado, Programa de Pós-Graduação em antropologia (PPGA), UFPE. (AMARAL, 2000). 
ser compartimentado, e ela é absolutamente capaz de aprender desenhando, brincando, dançando e contando aventuras, fazendo tudo ao mesmo tempo.

Nesse momento da dimensão tácita do discurso, se tem hora para tudo, hora...

Para dançar: uma criança começa a dançar e a professora diz: Chico não estou ouvindo música para você estar dançando!

Para descansar: A criança diz: Ai que descanso bom, vou descansar mais. E a professora: Já acabou a hora do descanso.

Para contar aventuras: A professora: Na hora do descanso você conta suas aventuras.

Para cantar: A professora pediu para que as crianças desenhassem na capa do convite da exposição dos seus desenhos; uma delas, enquanto desenhava, também cantava, e a professora perguntou: Lucas és tu?... e um colega, imediatamente: Ele está cantando. A professora: E é hora de cantar? É hora de que? Um dos alunos: Desenhar.

Essa é uma imagem que, além de provocar uma fragmentação entre o cantar e o desenhar, faz uma diferenciação entre o trabalho, que é simbolizado pelo desenhar; e o cantar, pelo brincar. Essa fragmentação reflete na criança, sobretudo quando ela é questionada sobre o que é arte. Dentre 40 crianças entrevistadas, sete disseram que arte é "desenhar"; onze, "pintar"; quatro, "pintar e desenhar", isto é, 27,5\%. Ainda: sete disseram que arte é "pintar, desenhar e fazer tarefa"; uma, "construir coisas"; uma, "um trabalho que faz quadros; arte é uma coisa que só o pintor consegue fazer; Quem trabalha lá na arte é tia Cristina; Praia, uma fazenda de boi e vaca [fazendo um desenho de uma fazenda], escritório".

É um percentual significativo, que mostra que as crianças, na sua maioria, só consideram arte "as artes plásticas", e sendo essas uma "expressão de trabalho".

A tradição do pensamento que forma o espírito das escolas elementares ordena que se reduza o complexo ao simples, quer dizer que se separe o que está ligado, que se unifique o que é múltiplo, que se elimine tudo o que traz desordens ou contradições para o nosso entendimento (MORIN, 1999, p.11).

Isso é também percebido nas atividades em que a escola opõe ou separa, de um lado, o lúdico, do outro, o "sério"; uma hora, a brincadeira e as aventuras, em outra hora, o "trabalho". Consequentemente, ações como representar, dançar e cantar, por exemplo, não podem ser desenvolvidas ao mesmo tempo em que o "trabalhar".

Imagens que opõem a brincadeira ao trabalho:

"Vamos trabalhar pra gente não se perder.": não se perder significa não se distrair, desconcentrar do "trabalho", pois, nesse mo- 
mento, enquanto as crianças fazem a atividade, elas conversam, contam histórias e cantam.

Professora:

Na hora do descanso você conta suas aventuras.

Maria, deixe de bobagem, ajeite a cadeira e termine o trabalho.

Trabalhar na hora certa.

Deixem de brincadeira!!!

Para passar do mito de Orfeu ao de Prometeu, a escola utiliza a figura mítica do Saci-Pererê como um mediador, um mensageiro entre a escola e as crianças. Mensageiros também, Hermes e Exu são identificados como Trikster, personagem que representa a primeira fase da infância, personagem travesso, alegre e brincalhão. Esses mitos foram tomando corpo no decorrer das análises das imagens e dos símbolos encontrados na pesquisa.

Saci, que é um perneta, aparece descrito, no Dicionário de Símbolos, de Chevalier e Gheerbrant (1999, p.710) da seguinte maneira: "entre os fons do Benin, a divindade Aruí, que deu o fogo aos homens, é representada como um homem muito pequeno, maneta, perneta com um olho só no meio da testa".

Podemos, então, confirmar a presença frequente do saci no imaginário das crianças, através dos testes AT-10 realizados, teste composto por desenho, história do desenho, dados pessoais e dados sobre os personagens arquetipais. Num dos testes, o Saci é explicitado no desenho, mesmo sem ser o personagem principal da história, e isso mostra a sua importância como um personagem que mantém uma mobilidade e uma "ciclicidade" velozes.

Numa outra história, que tem "morcegos" como personagens, aparece uma das versões do Saci-ave.

Os morcegos são apenas considerados agoureiros, quando revoam em grande quantidade. No Sul e no Centro suas proezas são empurradas para a culpa do Saci-Pererê, trançar as quinas dos animais, deixá-los fatigados (pela perda de sangue), furar as frutas guardadas, provocar os ruídos estranhos etc. (CHEVALIER E GHEERBRANT 1999, p. 710).

Os desenhos que as crianças fizeram para a pesquisa apresentaram símbolos que formam uma grande constelação de imagens, isto é, imagens que têm uma relação simbólica entre si. Os símbolos representados e encontrados nesta pesquisa permitiram desvendar os significados que constroem o universo estudado. A escola se utiliza da arte e de todo o seu mundo lúdico para penetrar na natureza da criança; e se utiliza também de elementos simbólicos que a impregnam para facilitar a apreensão, pela criança, dos conceitos transmitidos via ensino-aprendizagem. 
Ao observar as crianças, nas escolas investigadas, no seu cotidiano, na prática escolar junto à professora, fiz o levantamento de quais e quantas vezes as crianças citaram os símbolos que serão estudados, na etnografia. Tendo este material selecionado, fui confirmar se esses símbolos também aparecem nos testes AT-10 das crianças.

$\mathrm{Na}$ etnografia, encontrei: elementos da natureza (árvore - 8; sol - 7; arco-íris - 5; céu - 4; coração - 3); objetos (casa - 14; escada - 8; sanfona - 2); animais (peixe - 7; cobra - 6; galinha - 6; macaco - 5; caracol - 4; cavalo - 4; sapo - 3; onça - 3; barata - 2; besouro - 1; coruja - 1) e cores (amarelo - 17; rosa - 14; azul - 12; branco - 12; vermelho - 10; marrom - 7; verde - 7; roxo - 5; preto - 4; vinho - 3; laranja - 3; e cinza - 2), das quais não tratarei aqui.

Segui a investigação dos símbolos nos desenhos dos testes AT-10 aplicados em 25 crianças com idade entre quatro e seis anos, e o resultado é que as histórias, descritas sobre os desenhos realizados pelas crianças, têm um roteiro cíclico; apresentam personagens que se assemelham ao Saci; apresentam caminhos iniciáticos; e, às vezes, tudo acaba em brincadeira. A transformação é uma temática constante em seus desenhos e em suas representações.

Os símbolos encontrados nos testes AT-10, foram: árvore, cinco vezes: dessas, três vezes aparece como refúgio e duas como refúgio ameaçado pelo fogo, inclusive num deles a criança disse que gostaria de ser a água para apagar o fogo das árvores; animais, como: macaco, cavalo, cavalo-marinho, pássaro, peixe, cobra e casa. Dos 25 testes analisados, quatro são histórias de Rapunzel, príncipes, princesas, bruxas e fadas.

Quase todos os símbolos são coincidentes, entre a etnografia e os testes AT-10. Os símbolos relativos à "estrutura mística do imaginário" são: casa e peixe; entre as imagens da "estrutura sintética”, os símbolos: roda, caracol e árvore; e, sol e cavalo, são "heroicas".

O macaco é fortemente encontrado na etnografia. Ele tem grandes semelhanças com o Saci, no seu simbolismo, e dele pode ser enfatizada a sua agilidade, como o é para o povo tibetano; para o povo do Extremo Oriente, "o Rei-macaco alcança, enfim, o estado de Buda. A atitude do macaco, na arte do extremo oriente, é muitas vezes de sabedoria e desprendimento, talvez por desdém à pseudo-sabedoria do homem" (CHEVALIER E GHEERBRANT op. cit., p.573).

Assim como o Saci pode representar o Tot, no Egito "o cinocéfalo é a encarnação do Tot" (Ibdem). O Saci, como filho da lua, está ligado ao tempo e ao ciclo do calendário, pois Tot "rege as horas e o calendário, é o senhor do tempo" (Ibidem): "O macaco, bandido das estradas, aventureiro bem-humorado, que irrita, mas que desarma com suas brincadeiras, [como o Saci] é ilustrado pelo mito grego Cércopes [...] Esses Cércopes, da mitologia grega, são parentes muito próximos do Trikster.” (Idem, p. 574).

Além da forte presença do macaco, é também significativo o aspecto de engolimento:

Em um mito dos índios bororos, registrado por Calbacchini e Albisetti, citado por C. Lévi-Strauss (LEVEC, 135), o macaco que, 
naquela época era como um homem, aparece como herói civilizador: inventa a técnica de produzir fogo por atrito. $\mathrm{O}$ fato dele enganar o jaguar, que o engole e o desengole novamente, é significativo (Idem, p. 574).

Assim como o macaco o engole e o desengole, o peixe também tem essas características, além de ser um símbolo muito representativo para a criança e para a escola. O peixe é continente contido, isto é, guarda seres dentro de si, que podem sair do seu interior intacto; engole e desengole. Seres que retornam às suas origens, permitindo a circularidade.

O peixe é símbolo do continente redobrado, do continente contido. É o animal "encaixado" por excelência. Não tem sido suficientemente notado como o peixe é um animal que é pensado em todas as escalas, desde o minúsculo varão até o enorme "peixe" baleia (DURAND 1997, p. 215/216).

É essa inversão que inspira toda a imaginação da descida e especialmente o "complexo de Jonas”.

O Jonas é eufemização do engolimento e, em seguida, antífrase do conteúdo simbólico do engolimento [...] O engolimento não deteriora, muitas vezes até valoriza ou sacraliza [...] O engolimento conserva o herói que foi engolido, como a 'passagem' do cristóforo salvaguarda os passageiros (DURAND 1997, p. 206).

O peixe, como o grande engolidor, está fortemente representado nas histórias infantis como, por exemplo: no Soldadinho de Chumbo, de Hans Christian Andersen, e Pinóquio, de Walt Disney. Nos dois casos, os personagens principais são engolidos por peixes e saem ilesos de dentro deles, quer dizer, eles saem renovados e fortalecidos.

O Soldadinho de Chumbo é feito de chumbo por um artesão é vendido numa loja para presentes, vai parar entre os brinquedos de uma criança, cai na chuva, colocam-no num barquinho de papel que vai para o esgoto; no rio, é engolido por um peixe que vai ao mar, o peixe é pescado, vai para a peixaria, é comprado pela cozinheira da criança (dona do soldadinho) e é tirado do estômago do peixe e devolvido ao menino, cai no fogo e se transforma em coração de chumbo (AMARAL, 2000).

Nessa história, a ideia de circularidade está presente: é um ciclo do chumbo a volta do chumbo. Pode-se também observar o detalhe dessa história é que o soldadinho tem uma perna só, como o Saci.

A história de Pinóquio é semelhante à do Soldadinho de Chumbo, tanto no aspecto circular - Pinóquio é engolido, vai parar na barriga de uma baleia, onde a faz espirrar, conseguindo sair e voltar para Gepeto, seu dono-pai, para casa - quanto à baleia ou ao peixe, que representam a circularidade. Segundo Chevailer e Gheerbrant (1999, p.703/604), “o peixe está associado ao nascimento ou à restauração cíclica [...] Além disso, o peixe é ainda símbolo de vida e fertilidade, em função de sua prodigiosa faculdade de reprodução e do número infinito de suas ovas [...]." 
O peixe é um animal que está intimamente ligado à cidade do Recife, cidade portuária e cortada de rios e pontes, sendo caracterizada litorânea, com o mar em toda a sua extensão. E, por isso, o peixe serve de inspiração para muitos dos artistas pernambucanos. O peixe é o símbolo geral dos outros incontinentes, havendo uma rítmica cíclica do engolimento, o que remete aos arquétipos cíclicos.

Pela etimologia indoeuropeia que Jung sublinha: o sânscrito val, valati, significa ao mesmo tempo cobrir, envolver, encerrar e também enrolar-se: valli é a planta que se enrola, donde o volutus latino, que sugere seja a imagem da serpente enrolada, seja a que significa membrana, ovo, vulva.

A serpente ou a cobra também é muito representada pelas crianças, em vários momentos da observação: modelando massinha; fazendo atividades de educação física; conversando na hora do descanso, e numa das histórias do teste AT-10: "A Cobra Coral". Assim, "o simbolismo do peixe parece pôr a tônica no caráter involutivo e intimista do engolimento, enquanto a serpente presta-se, sobretudo, ao simbolismo do ciclo".

Como o peixe, a casa também é um símbolo místico. Representando a harmonia, ela permite o aconchego e é imagem de intimidade repousante: a casa significa o ser interior, segundo Bachelard; seu porão e sótão simbolizam diversos estados da alma... A casa é um símbolo feminino, com o sentido de refúgio, da mãe, de proteção, de seio materno.

As crianças desenham casas, citam cores de casa ao ver a professora misturar tintas. A casa é um espaço de segurança para a criança, o qual é muito citado nos testes AT-10; diversas vezes.

Das 25 histórias dos AT-10 analisados, em oito delas as crianças dizem que o personagem vai para casa, sempre como uma forma de proteção, um lugar que depois de tudo serve para descansar e ficar em paz.

Espaço feliz já tão citado que é a escola de educação infantil, espaço também de segurança, uma segunda casa para as crianças, está relacionada ao Recife e ao rio Capibaribe, constelação de imagens relacionadas aos símbolos encontrados: a casa e o peixe.

Nesse vai e vem de símbolos: peixe, cobra, casa, na análise da pesquisa podemos observar como eles estão tão entrelaçados e como suas constelações são claras e pertinentes.

\section{Referências}

AMARAL, Maria das Vitórias Negreiros do. A criança desvendando a arte. Um olhar antropológico. Dissertação. (Mestrado em Antropologia). Recife: UFPE, 2000.

BACHELARD, Gaston. A Poética do Espaço. Tradução de Rosemary Costhek Abílio. São Paulo: Martins Fontes, 1998. (Coleção Tópicos)

.A Água e os Sonhos: ensaio sobre a imaginação da matéria. Tradução de Antônio de Pádua Danesi, São Paulo: Martins Fontes, 1997, 202p. (Coleção Tópicos). 
O Direito de Sonhar. Tradução de José Américo Motta Pessanha... [et. al.]. Rio de janeiro: Bertrand Brasil, 1994(1), 202p.

BARBOSA, Ana Mae. (org). Inquietações e mudanças no Ensino da Arte. São Paulo: Cortez Editora, 2002, 183p.

John Dewey e o Ensino da Arte no Brasil. 3. ed.rev. São Paulo: Cortez Editora, 2001, p. 198.

. Tópicos Utópicos. Belo Horizonte: C/Arte, 1998. p. 198.

.(org.). Arte-Educação: Leitura no Subsolo. São Paulo: Cortez, 1997(1). p. 199.

. Artes Plásticas no Nordeste. In.: Estudos Avançados. 11 (29). 1997(2), pp. 241-254.

. Arte no Brasil: várias minorias. Tradução de Cyana Leahy, in Voices of Color: art and society in the Americas by, Phoebe M. Farris-Dufrene, 1997(3).

BRUNEL, Pierre (org.) Dicionário de Mitos Literários. Tradução de Carlos Sussekind [et al], Rio de Janeiro: José Olimpyo. 1997, p. 939.

DUBORGEL, Bruno. Imaginaire et Pédagogie: de l'íconoclasme scolaire à la culture des songes. Paris: Editions Privat, 1992.

DURAND, Gilbert. O Imaginário: ensaio acerca das ciências e da filosofia da imagem. Tradução de René Eve Levié, 3. ed., Rio de Janeiro: DIFEL, 2004. sofia)

. Imaginação Simbólica. São Paulo: Cutrix, 1998. p. 128. (Coleção Enfoques, Filo-

. As Estruturas Antropológicas do Imaginário: introdução à arqueologia geral. Tradução Hélder Godinho. São Paulo: Martins Fontes, 1997, p. 551.

. Campos do Imaginário. Tradução de Maria João Batalha Reis, Lisboa: Ellug, 1996. p. 283. (Coleção Teoria das Artes e Literatura).

EFLAND, Arthur. Imagination in Cognition: the purpose of the art. In.: The International Journal of Arts Education, volume 1, number 1, pp.26-50, May/2003.

EISNER, Elliot W. The Arts and the Creation of Mind. New Haven/London: Yale University Press, 2002.

ELIADE, Mircea. Imagens e Símbolos: ensaio sobre o simbolismo mágico-religioso. Tradução de Sonia Cristina Tamer, São Paulo: Martins Fontes, 1996, p. 178.

LÉVI-STRAUSS, Claude. Olhar, Escutar e Ler. Tradução de Beatriz Perrone-Moisés, São Paulo: Companhia das Letras, 1997, p. 151.

MAFFESOLI, Michel. No Fundo das Aparências. Tradução de Bertha Halpern Gurovitz 
- Petrópolis, RJ: Vozes, 1996, p. 350.

O Tempo das Tribos: o declínio do individualismo nas sociedades de massa. 2.ed. Rio de Janeiro: Forense Universitária, 1998, p. 231.

MORIN, Edgar. Complexidade e Transdisciplinaridade: reforma da universidade e do ensino fundamental. Tradição de Edgard de Assis Carvalho. Natal: Editora da UFRN, 1999 , p. 58.

.O Método 4 - as ideias, habitat, vida, costumes, organização. Tradução de Juremir Machado da Silva. Porto Alegre: Sulina, 1998, p. 288.

Ensaio de Complexidade. Coordenação de Gustavo de Castro [et. al.]. Porto Alegre: Sulina, 1997 (1), p. 272.

. O Método 3. o conhecimento do conhecimento. Tradução de Maria Gabriela de Bragança, Portugal: Pubicações Europa-América, 1996, p. 230.

O Paradigma Perdido: a natureza humana. Tradução de Hermano Neves. Portugal: Mem Martins - Publicações Europa-América Ltda, 2000, p. 222.

PRANDI, Reginaldo. Mitologia dos Orixás. São Paulo:Companhia das Letras, 2001.

ROCHA PITTA, Danielle Perin. As Estruturas do Imaginário na Arte e na Educação. In.: Seminário sobre Literatura Infanto-Juvenil. São Paulo: MEC/ FACULDADE TEREZA MARTIM/ UNESP/ USP, 1995.

SANCHEZ TEIXEIRA, Maria Cecília. Discurso Pedagógico, Mito e Ideologia: o imaginário de Paulo Freire e de Anísio Teixeira. Rio de janeiro: Quartet, 2000, p. 96.

. e Maria do Rosário Silveira Porto (orgs.) Imagens da Cultura: um outro olhar. São Paulo: Editora Plêiade, 1999, p. 161.

Imaginário e Ideário no Discurso Pedagógico de Anísio Teixeira e de Paulo Freire (Palestra). In.: IV Ciclo de Estudos: Seminários sobre Cultura e Imaginário, Centro de Estudos do Imaginário. Culturanálise de Grupos e Educação. CICE/FEUSP. 15 abr. 1999.

. e Maria do Rosário Silveira Porto (orgs.). Imaginário, Cultura e Educação. São Paulo: Editora Plêiade, 1999 (1).

CHEVALIER, Jean e Alain Gheerbrant. Dicionário de Símbolos: mitos, sonhos, gestos, formas, figuras, cores, números. Coordenação de Sussekind e Tradução de Vera da Costa e Silva, [et al.] 13. ed. Rio de Janeiro: José Olympio, 1999.

WUNENBURGER, Jean-Jacques. Philosophie des Images. 1. ed. Paris: Éditions Universitaires, mars de 1997. 